\title{
A persistência das feiras de agricultores familiares em um cenário de "sojificação da sociedade": elementos da realidade de Júlio de Castilhos e Tupanciretã/RS
}

\author{
The persistence of family farmers' fairs in a "sojification of society" scenario: elements \\ of reality of Júlio de Castilhos and Tupanciretã / RS
}

Tatiana Aparecida Balem', Ethyene de Oliveira Alves"

\begin{abstract}
Resumo
Uma forma de resgate e manutenção da cultura alimentar é por meio dos mercados de circuito curto, principalmente as feiras de agricultores. Assim, o trabalho visa uma investigação dos consumidores e agricultores feirantes, considerando que o fornecimento de alimentos, através das feiras municipais, propicia além de emprego e renda aos agricultores, também, qualidade de produto aos consumidores. Neste espaço é possível comercializar e agregar valor aos produtos oriundos da agricultura familiar, além de criar elos de relação social. Neste sentido, aplicamos questionários com perguntas mistas em ambas categorias, agricultores e consumidores, nas feiras de Júlio de Castilhos e Tupanciretã. Observamos que há uma grande assiduidade por parte dos consumidores e também uma preferência por determinado agricultor. As feiras podem ser analisadas sob vários aspectos: a importância das feiras como espaços diferenciados de consumo; a identificação das feiras como locais onde é possível comprar um alimento de melhor qualidade; a busca por parte dos consumidores por alimentos com identidade cultural; a dimensão da contribuição social que as feiras possuem, no que tange a geração de renda para os agricultores; e um dos aspectos mais importantes, a consolidação de um espaço diferenciado e com identidade de agricultura diferente da hegemônica dos municípios.
\end{abstract}

Palavras-chave: Alimentação saudável; Consumidores. Feira de agricultores; Desenvolvimento rural;Agricultura familiar

\begin{abstract}
One way to rescue and maintain the food culture is through the short circuit markets, principally farms fairs. Thus, the work aims at an investigation of consumers and family farmers fairs, considering that the supply of food, through the municipal fairs, provides employment and income to farmers, but also product quality to consumers. In this space it is possible to commercialize and add value to the products coming from the family agriculture, besides creating links of social relation. In this sense, we applied questionnaires with mixed questions in both categories, consumers and farmers, at Júlio de Castilhos and Tupanciretã fairs. We observe that there is great assiduity on the part of consumers, and also a preference for a particular farmer. The fairs can be analyzed in several aspects: the importance of fairs as differentiated spaces of consumption; The identification of fairs as places where it is possible to buy a better quality food; The search by consumers for foods with cultural identity; The size of the social contribution that the fairs have, regarding the generation of income for the farmers; And one of the most important aspects is the consolidation of a differentiated space with an agricultural identity different from the hegemonic identity of the municipalities.
\end{abstract}

Keywords: Healthy eating.; Consumers; Farmers fair; Rural development; Family farming

\footnotetext{
I Doutora em Extensão Rural pela Universidade Federal de Santa Maria - tatianabalem@yahoo.com.br

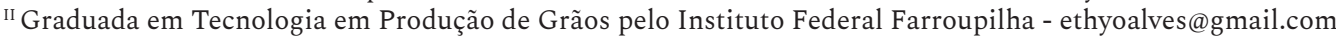




\section{Introdução}

A era da industrialização, concomitantemente com a série de descobertas técnico-científicas, vem colaborando de maneira marcante para a transformação de vida da sociedade, principalmente aos costumes alimentares da população brasileira (FRANÇA et. al., 2012). São notórias as mudanças de hábitos alimentares na tentativa de agregar tempo e praticidade, além da influência do processo de "modernização da vida", onde o consumo de produtos industrializados acaba substituindo produtos alimentares in natura ou minimamente processados. Nesse contexto, os hábitos alimentares modificaram-se ocorrendo um substitucionismo dos alimentos enraizados na cultura e na produção local por alimentos industriais e globais, resultado do processo de "imposição" e construção de uma ideia de consumo pela indústria alimentar (POULAIN, 2004).

Por outro lado, segundo Buchler, Smith e Lawrence (2010) é crescente a preocupação dos consumidores com os alimentos industrializados e alheios a sua cultura que estão ingerindo. Dessa forma, embora a industrialização tenha impactado de forma significativa a alimentação, erodindo os meios tradicionais de consumir, há uma crescente consciência dos riscos alimentares dos alimentos industriais. Somado a esse fator, podemos citar outros dois fatores significativos: 1- Para Wiskerke (2009), a globalização e a industrialização do abastecimento alimentar não desligaram o alimento por completo do seu contexto sociocultural e territorial; 2- Goodman (2003) descreve o movimento qualiy turn da alimentação, ou seja, o fortalecimento de redes alternativas de produção e comercialização de alimentos, que questionam o modelo alimentar industrial trazem um renovado interesse no local, onde imersão, confiança e reciprocidade são noções chaves.

Essas questões, de certa forma, explicam a sobrevivência das feiras de agricultores familiares ao longo do processo de industrialização da agricultura e indução do consumo de produtos processados e ultraprocessados pela indústria alimentar. Hábitos alimentares que foram comuns no passado hoje retornam como formas positivas de manter uma cultura alimentar cada vez mais saudável. As feiras de agricultores familiares, assim podem ser analisadas em duas vias: 1- uma forma de fornecer alimentos com maior qualidade e diversidade para a sociedade, com produtos com menor nível de industrialização, com garantia de procedência e qualidade; 2 - além de ser uma fonte de renda significativa para a agricultura familiar.

De acordo com Padilha et. al. (2005), a sociedade reconhece a agricultura familiar pela "cultura diferenciada" em ações que permeiam a preservação da vida comunitária e o meio ambiente, contribuindo na expectativa de uma vida melhor. Como destacam Scarabelot e Schneider (2012), às cadeias agroalimentares curtas remetem a uma forma de comercialização onde existe a proximidade entre agricultor e consumidor, conexão essa que permite a interação facilitando que ambos conheçam os propósitos um do outro.

Os municípios de Júlio de Castilhos e Tupanciretã apresentam características de evolução dos sistemas agrários muito similares, ou seja, ocupação inicial com o latifúndio pastoril com base na criação de gado de corte e nas décadas de 80 e 90 transformações dos sistemas pastoris para sistema de monocultivo de soja e desapropriação de algumas áreas para assentamentos de reforma agrária. Embora esses municípios sejam identificados como grandes produtores de soja, sendo esse o ideário dominante do rural, possuem feiras de agricultores familiares. Das feiras participam agricultores assentados e não assentados.

Com o intuito de conhecer as formas de inserção desses espaços de comercialização direta de produtos típicos da produção familiar no cenário dominante do agronegócio, desenvolvermos uma investigação envolvendo agricultores feirantes e consumidores. Com os agricultores abordamos questões produtivas, de processamento artesanal e de comercialização. Com os consumidores o foco foi e estudar como este público percebe a feira e o que condiciona os mesmos a optar por esse espaço de comercialização. Esse artigo traz as reflexões que a pesquisa proporcionou desse pequeno universo de comercialização direta e inter-relação entre agricultores familiares e consumidores. Para tanto, organizamos o material em cinco seções, a primeira compõe esta introdução a qual retrata nossa justificativa da pesquisa. A segunda proporciona a compreensão do processo investigativo e da realidade estudada. A terceira seção que aborda os agricultores feirantes, o espaço feira e as formas e inserção deste espaço na realidade agrícola dos dois municípios. A terceira seção também traz a caracterização dos consumidores das feiras e as percepções que esses possuem desse espaço diferenciado de comercialização. E por fim, as considerações sínteses que foram possíveis realizar com o trabalho.

\section{Compreensão do processo investigativo e do local de estudo}

Os municípios de Júlio de Castilhos e Tupanciretã localizam-se na mesorregião do centro ocidental do estado do Rio Grande do Sul. São municípios reconhecidos no cenário estadual do agronegócio pela expressividade da cultura da soja. A soja ocupa 94,64\% e 97,83\% das lavouras temporárias de verão em Júlio de Castilhos e Tupanciretã, respectivamente (IBGE, 2017). O quadro 01 apresenta as áreas em hectares ocupadas com culturas de verão dos dois municípios. 
Quadro 01- Área ocupada, em hectares, com as lavouras temporárias de verão no município de Júlio de Castilhos e Tupanciretã/RS

\begin{tabular}{l|c|c}
\hline \multirow{2}{*}{ Cultura } & \multicolumn{2}{|c}{ Área plantada em hectares } \\
\hline Soja & Júlio de Castilhos & Tupanciretã \\
Milho & $106.501,6$ & $139.642,5$ \\
Batata inglesa & $2.652,6$ & $5.042,7$ \\
Feijão & 99,4 & 0,6 \\
Mandioca & 14,0 & 1,3 \\
Girassol & 59,0 & 85,0 \\
Fumo & 88,0 & 0 \\
Batata Doce & 44,0 & 31,0 \\
Amendoim & 51,0 & 6,0 \\
Melancia & 2,0 & 3,0 \\
Alho & 2,0 & 3,0 \\
Melão & 0,01 & 0,6 \\
Total & 0,4 & 1,0 \\
Fonte: IBGE (2017) & $109.514,0$ & $144.816,7$ \\
\end{tabular}

O município de Júlio de Castilhos foi emancipado em 14 de julho de 1891 e conta com um total populacional de 19.579 habitantes (IBGE, 2010), sendo que $17,74 \%$ desse total vivem no meio rural (IBGE, 2006). No município existem cerca de 1.400 estabelecimentos rurais dos quais cerca de 900 são unidades de produção familiar e destes, 265 são unidades de famílias assentadas em quatro Assentamentos de Reforma Agrária (EMATER-RS/ ASCAR, 2009). O município tem na herança os sistemas produtivos baseados na grande propriedade, sendo num primeiro momento na criação de gado extensivo e atualmente com predominância da agricultura empresarial, principalmente voltada para as lavouras de grãos, onde se destaca o monocultivo da soja (MOREIRA, 2008).

O município de Tupanciretã possui a evolução dos sistemas agrários muito semelhante a Júlio de Castilhos, passou do latifúndio pastoril para o latifúndio monocultor de soja. Tupanciretã foi emancipado em 21 de dezembro de 1928 , possui 22.281 habitantes dos quais $19,12 \%$ vivem no meio rural distribuídos em 1.336 estabelecimentos agropecuários (IBGE, 2006). Tupanciretã possui também expressiva presença de assentamentos de reforma agrária, totalizando dezessete assentamentos rurais e 706 famílias assentadas (MOREIRA e MEDEIROS, 2009). O município é o maior produtor de soja do Rio Grande do Sul (FEE, 2014). A agricultura familiar do município de Tupanciretã é expressivamente representada pelos assentamentos de reforma agrária, que configuraram uma estrutura produtiva mais diversificada. A agricultura familiar é responsável pelos cultivos de soja, milho, feijão, mandioca, arroz, hortifrutigranjeiros dentre outros produtos agrícolas e também vem, ao longo dos anos, intensificando a atividade leiteira e outros produtos que são tanto para autoconumo familiar como para comercialização.

Nos dois municípios há presença de feiras realizadas por agricultores familiares e agricultores assentados de reforma agrária. Em Júlio de Castilhos há duas feiras, a Feira dos Agricultores Familiares de Júlio de Castilhos e a Feira de Produção da Reforma Agrária e da Agricultura Familiar - FEPRAF. Em Tupanciretã há a Feira de produtos Coloniais da Reforma Agrária. Com a perspectiva de estudar a importância das feiras de agricultores nesse cenário agrícola "sojificado", dos municípios de Júlio de Castilhos e Tupanciretã, realizamos uma pesquisa através de questionários aplicados em agricultores feirantes e consumidores das feiras citadas. Tais questionários eram compostos de perguntas mistas (objetivas e discursivas) admitindo assim o caráter qualitativo. No questionário direcionado aos agricultores foram abordados aspectos relacionados à diversidade produtiva, sistemas de produção, processamento artesanal, gerenciamento da propriedade, apoio e assessoria e comercialização. Foram aplicados questionários em 24 agricultores, sendo 18 em Júlio de Castilhos e 6 em Tupanciretã. No questionário direcionado aos consumidores alguns aspectos abordados 
eram: conhecimentos básicos sobre os produtos adquiridos nas feiras, frequência e motivos para ir à feira, critérios considerados para comprar produtos, etc. O total da amostra de consumidores, envolvendo as três feiras foi de 70 questionários aplicados. A análise qualitativa será orientada pela análise interpretativa. Para Gomes (2012) a análise interpretativa busca a lógica interna dos fatos, dos relatos e das observações e os situa no contexto dos atores.

\section{Agricultura familiar: a feira como um dos caminhos para o reconhecimento em um cenário agrícola "sojificado"}

A cultura da soja passou de 949 mil hectares na safra 1976/77, para 33.251,9 mil hectares (ha) na safra 2015/16 no Brasil, sendo o estado do RS o terceiro maior produtor de soja, com uma área plantada de 5,692 milhões de hectares (CONAB, 2016). Tupanciretã é considerado o município maior produtor de soja do RS e Júlio de Castilhos o segundo maior produtor, como pode ser observado no quadro abaixo. Importante salientar que se for observado à área cultivada com culturas de verão é possível observar a completa hegemonia da cultura da soja nesses municípios.

Quadro 02 - Ranking dos dez municípios maiores produtores de soja no estado do Rio Grande do Sul em 2017

\begin{tabular}{|l|c|c|c|c|c|c|}
\hline \multirow{2}{*}{ Município do RS } & \multicolumn{5}{|c|}{ Área plantada em hectares } & Toneladas \\
\cline { 2 - 7 } & $\begin{array}{c}\text { Lavoura } \\
\text { Permanente }\end{array}$ & $\begin{array}{c}\text { Lavoura } \\
\text { Temporária }\end{array}$ & $\begin{array}{c}\text { Pastagem } \\
\text { Natural }\end{array}$ & $\begin{array}{c}\text { Pastagem } \\
\text { cultivada }\end{array}$ & Soja & $\begin{array}{c}\text { Quantidade } \\
\text { de soja }\end{array}$ \\
\hline Tupanciretã & $3.069,7$ & $144.816,7$ & $26.610,0$ & $13.991,0$ & $139.642,5$ & $496.303,1$ \\
\hline Júlio de Castilhos & 115,3 & $109.514,0$ & $26.841,6$ & $6.135,005$ & $106.501,6$ & $400.300,5$ \\
\hline Cruz Alta & 139,9 & $102.339,2$ & $4.836,5$ & $5.641,910$ & $90.871,7$ & $335.237,3$ \\
\hline São Gabriel & $6.042,9$ & $152.760,4$ & $234.567,3$ & $28.037,141$ & $117.893,5$ & $319.567,4$ \\
\hline Santa Bárbara do Sul & $1.902,4$ & $79.417,8$ & $1.739,0$ & $1.901,00$ & $76.217,3$ & $305.818,1$ \\
\hline Palmeira das Missões & 270,3 & $93.351,68$ & $2.420,7$ & $2.548,800$ & $81.077,1$ & $303.018,8$ \\
\hline Cachoeira do Sul & $2.849,6$ & $143.329,9$ & $89.466,3$ & $23.972,20$ & $99.596,4$ & $297.239,2$ \\
\hline Jóia & 312,3 & $73.463,6$ & $14.077,5$ & $6.312,8$ & $68.915,1$ & $217.297,3$ \\
\hline São Luiz Gonzaga & 192,7 & $64.047,5$ & $28.119,3$ & $6.354,16$ & $58.640,9$ & $195.716,9$ \\
\hline São Miguel das Missões & 206,9 & $65.901,1$ & $25.556,9$ & $5.754,25$ & $59.082,2$ & $193.254,1$ \\
\hline
\end{tabular}

O avanço e expansão do cultivo da soja, no estado do RS, vem causando uma grande pressão nos ecossistemas e comunidades locais. Esse processo, resulta em concentração de renda e terra, êxodo rural e uma percepção social e produtiva "quase religiosa", a que chamamos de "sojificação da sociedade". O termo "sojificação da sociedade" explica o domínio técnico, econômico, de infraestrutura de apoio à produção (insumos, assistência técnica, serviços, máquinas, crédito agrícola) e de mercados estabelecidos voltados basicamente para a soja em regiões inteiras.

Outro elemento fundamental desse processo é a tendência geral da sociedade de desvalorizar qualquer iniciativa de agricultura fora do modelo do monocultivo da soja. Nessa última afirmação reside a explicação da percepção "quase religiosa”, pois parâmetros técnicos, produtivos e de mercados são completamente ignorados, quando se trata de outras culturas agrícolas ou outras formas produtivas, desta forma, o conhecimento científico acaba tomando "ares de conhecimento religioso”. Percebe-se uma sobrevalorização da cultura da soja e a mesma é considerada como a única via possível. Quaisquer outras inciativas de agricultura são vistas, de forma hegemônica, como "pequenas” e com poucas perspectivas de sucesso. As agricultoras e agricultores feirantes relatam essas questões com frequência. Algumas agricultoras que fazem feira afirmam que a atividade periférica, ou seja, a feira, é de domínio das mulheres, para os maridos a produção de soja é mais importante. Um dos agricultores feirantes relata, "as pessoas questionam a agricultura da feira, dizem que não dá dinheiro, tem muito pequeno que planta soja e diz que o resto não dá dinheiro, mas não percebem que soja para pequeno também não dá dinheiro”. Outro agricultor assentado 
relata: “aqui no assentamento tá todo mundo plantando soja, não sei explicar, parece que o povo esqueceu o que é produzir outras coisas, e o pior que os venenos da soja estão matando tudo, então logo não vai dar mais para produzir outras coisas mesmo".

De acordo com Kuhn (2011) a ciência organiza-se por paradigmas científicos e depois que um paradigma científico está totalmente estabelecido, há uma tentativa de forçar a natureza a encaixar-se dentro dos limites preestabelecidos e relativamente inflexíveis do paradigma. A “sojificação” encerra-se no paradigma da modernização conservadora da agricultura, no entanto ocorre a defesa irrestrita de uma única cultura agrícola como viável, ignorando completamente os feitos ambientais e econômicos na agricultura familiar, por exemplo. E a ênfase de instituições na esfera da administração pública, de ensino, de extensão e de pesquisa, direcionando o conhecimento técnico para a cultura da soja, leva os experts da soja a exercer uma "certa autoridade" sobre os outros profissionais, aproximando a discussão que deveria ser científica, com a disseminação do saber religioso, que se pauta pela autoridade. Para Laville e Dionne (1999) o conhecimento religioso usa da autoridade para se manifestar, visto que a explicação do mesmo muitas vezes não tem sentido e a sua origem não tem evidência. Para Morin (1999) durante o maior período da humanidade o fundamento em filosofia era Deus. No entanto, frente à evolução do conhecimento filosófico e científico a ciência foi se distanciando da crença religiosa e estruturou-se como conhecimento autônomo e independente (MORIN, 1999). Mas Khun (2011) discute as estruturas estabelecidas e aceitas no paradigma científico, ou seja, um modelo ou conjunto de preceitos a serem adotados, aceitos e considerados válidos pela comunidade científica. Para Khun a comunidade científica hegemônica comunga de uma doutrina científica. No mesmo sentido, Morin (1999b) aponta que o surgimento da ciência como paradigma de conhecimento no século XX, que busca expulsar o mítico e trazer a "razão científica” como determinante da ação humana, o faz de maneira ideológica, que se camufla de ciência. É nessa discussão de Morin e de Khun que nos baseamos para definir o processo de sojificação da sociedade, ou seja, uma opção ideológica, alicerçada na modernização conservadora da agricultura, que busca a todo custo defender o ideário das commodities como única via possível, excluindo outras formas de agricultura e nesse contexto, desvalorizando sobremaneira a agricultura familiar. Mesmo nesse cenário, onde o paradigma da monocultura, e neste a cultura da soja, impera como determinante de modelo agrícola, existem feiras de agricultores familiares. Como as feiras persistem nesse cenário?

A Agricultura Familiar brasileira foi conceituada e reconhecida socialmente enquanto segmento com características específicas e com relevância econômica para o desenvolvimento do país, apenas a partir de meados da década de 1990 (GUANZIROLI e CARDIM, 2000; GUANZIROLI, BUAINNAIN E SABBATO, 2012). No entanto, este processo de reconhecimento é lento e contraditório, pois no cenário rural brasileiro, ainda há concepções que tendem a desvalorizar a Agricultura Familiar. Segundo Buainnain, Romeiro e Guanziroli (2003), questões como êxodo rural, o envelhecimento da população rural, a "ineficácia” dos agricultores familiares em acompanharem o progresso técnico, e suposta eficiência da agricultura empresarial, continuavam nos anos 2000 corroborando com a interpretação de que a Agricultura Familiar tendia a enfraquecer ao longo do tempo.

Guanziroli, Buainnain e Sabbatto (2012), salientam que a Agricultura Familiar, até o documento "Novo Retrato da Agricultura Familiar: o Brasil Redescoberto” publicado pelo MDA e FAO em 2000, era reconhecida como a "pequena produção", sendo que a unidade familiar era vista como "depósito e reserva de mão de obra". Deste modo, torna-se lógico que as instituições de ensino na área agrícola continuassem priorizando as demandas de um segmento visto hegemonicamente como o eixo central da futura agricultura brasileira, o denominado popularmente de "agronegócio". Isso, na verdade busca identificar uma agricultura fortemente inserida e subordinada ao sistema alimentar industrial. Ou seja, o paradigma dominante.

No entanto, este cenário passa a mudar na virada de século. Passa-se a destacar que no caso Brasileiro, a participação da Agricultura Familiar na economia e no abastecimento interno de produtos alimentícios é de grande relevância, como evidenciam os dados publicados por MDA (2009). Por outro lado, os circuitos curtos de comercialização, onde os produtos são comercializados no escopo da própria região onde são produzidos abastecem-se, principalmente, pela Agricultura Familiar.

Segundo Cerqueira, Rocha e Coelho (2006) "a agricultura familiar formou estratégias de reprodução que, contraditoriamente ao papel destinado a esse tipo de produção na política agrícola, manteve sua importância no espaço rural brasileiro”. Essa afirmação de Cerqueira, Rocha e Coelho (2006) ilustram o caso estudado nesse artigo, pois os municípios sofrem de um processo de “sojificação" do cenário econômico e agrícola, nesse sentido a AF é marginalizada sobremaneira. Um exemplo nesse sentido é a forte influência da cultura da soja nos assentamentos de reforma agrária. Os agricultores, não raro, afirmam que por falta de alternativas produtivas e de mercados diferenciados, resta como opção produtiva a soja e a produção de leite. Segundo Balem, Marostega e Secretti (2011), os assentamentos de Júlio de Castilhos reproduzem o modelo agrícola dominante na região, ou seja, com forte influência da cultura da soja. O que chamamos de "sojificação" é o domínio técnico, de infraestrutura de apoio à produção (insumos, assistência técnica, serviços, máquinas, crédito agrícola) e de mercados estabelecidos, voltados basicamente para a soja. Outro elemento fundamental desse processo é a tendência geral da sociedade de desvalori- 
zar qualquer iniciativa de agricultora fora do modelo do monocultivo. Os agricultores afirmam que se precisam de uma informação relacionada à cultura da soja, conseguem a mesma em vários lugares no município. No entanto, se precisam de uma informação sobre a produção de cenoura, beterraba ou outra hortaliça, é muito difícil conseguir e não raro, acabam sem a informação ou orientação necessária.

O contexto agrário dos municípios de Júlio de Castilhos e Tupanciretã é amplamente dominado pelo latifúndio, onde o monocultivo de soja ocupa papel relevante, sendo determinador da estrutura comercial, de serviços e de ideias. Neste sentido, estudar a inserção da categoria “agricultor familiar" nesse cenário de predominância de commodities é necessário, inclusive para fazer um contraponto a esse ideário quase hegemônico, de que a cultura da soja é "a única via agrícola”.

A categoria social denominada “agricultura familiar” é definida legalmente a partir da Lei nº 11.326, de 24 de julho de 2006. No entanto, Picolotto (2015) salienta que a categoria "agricultor familiar" "é resultado de um trabalho de construção política e de sentidos” (p. 65), sendo cunhada a partir de três conjuntos de atores: as organizações dos agricultores, os trabalhos dos acadêmicos e as políticas públicas e marco legal que definiram os itens a serem compreendidos nessa categoria. Sendo assim, a agricultura familiar não é uma categoria social recente, ela já obteve várias denominações ao decorrer do tempo, como "camponês", "lavrador", "colono". Mesmo sendo reconhecida apenas a partir de 1996 no cenário das políticas agrícolas, a AF continua com papel preponderante no fornecimento de produtos para a mesa da sociedade brasileira. Em se tratando de cultura alimentar e preservação do patrimônio imaterial relacionado à alimentação, a AF ocupa papel central e preponderante (BALEM e SILVEIRA, 2015). Outro aspecto importante é a conservação on farm das espécies de interesse agrícola. As variedades conservadas localmente pelos agricultores familiares, povos tradicionais e agricultores ecológicos "são consideradas reservatórios naturais de genes com potencial de uso para a produção sustentável de alimentos, fibras e medicamentos” (NODARI e GUERRA, 2015).

Dada a real importância da AF e considerando o abastecimento alimentar, há um destaque por nela se desenvolver culturas variadas e que, apesar da pequena escala, distinguem-se por sua qualidade e por sua característica altamente distribuída. Sua dispersão geográfica a aproxima dos consumidores, privilegiando principalmente as comunidades mais distantes das grandes cidades e, por consequência, dos grandes centros de distribuição. Também possibilita a geração de renda nessas regiões mais distantes dos centros industrializados, oferecendo alternativas, inclusive, para reprodução social das famílias agricultoras.

Nos municípios estudados, percebemos uma tensão entre as noções agricultura familiar x agronegócio. Como a soja ocupa papel central no cenário do agronegócio e essa cultura está presente em uma estrutura fundiária extremamente concentrada, o ideário de "sucesso" na agricultura está fortemente vinculado ao agronegócio. Nesta região, a AF familiar ocupa papel secundário e muitas vezes como sinônimo de "ineficiência”, pois a comparação está majoritariamente relacionada ao agronegócio da soja. Se analisarmos a oferta de serviços, insumos, máquinas e equipamentos voltados à produção agrícola percebe-se uma infraestrutura relacionada à soja. Uma das principais dificuldades dos feirantes é encontrar informação, insumos, sementes e maquinário adequado às demandas da produção para as feiras.

Outra questão que merece destaque são as poucas agroindústrias familiares legalizadas nos municípios, são apenas uma em Júlio de Castilhos e quatro em Tupanciretã. Os feirantes manifestam que nos municípios há uma dificuldade significativa em acessar informações agrícolas que não estejam relacionadas à soja. Com relação à orientação técnica e produtiva, os agricultores feirantes afirmam que possuem assistência pontual e relacionada à algumas questões, muito mais voltada à própria organização da Feira. No entanto, 46\% dos agricultores feirantes afirmou que não recebe nenhum tipo de orientação técnica relacionada a produção.

Mesmo nesse cenário "sojificado", percebemos nas feiras investigadas uma grande variedade de produtos. Sendo que os produtos in natura, frescos mais comercializados são: abóbora e moranga, saladas verdes (alface, rúcula, radiche, mostarda, agrião, etc...), tempero verde, pepino, batata doce, mandioca com casca, tomate, cenoura, beterraba, repolho e couve, caracterizando que os consumidores buscam cada vez mais diversidade de produtos, produtos "mais" naturais, como afirmam. E a "certificação" é baseada na relação de confiança entre produtor e consumidor. Os grãos comercializados são feijão e amendoim, apenas. As frutas que estão presentes na feira são principalmente cítricas como laranja, bergamota e limão, no entanto, os agricultores também comercializam, em menor escala, pêssego, uva e goiaba, cenário este que deveria ser mais explorado pelos produtores, pois há demanda pelos consumidores. Ainda percebemos, mas em menor proporção, frutas nativas como ariticum, ingá e butiá, deixando clara a diversidade de produtos apresentados pelos agricultores e a apreciação dos consumidores por produtos regionais.

Sobre os produtos de origem animal, o ovo é o alimento mais comercializado e mais procurado pelos consumidores, seguido de queijo e leite, carne de frango e peixes, sendo esse último em menor proporção. Vários fatores são limitantes ao consumo destes produtos, o principal deles são as barreiras legais que exigem certificação de inspeção sanitária. No entanto para que ocorra a inspeção dos produtos de origem animal há o imperativo da estrutura física agroindustrial o que os agricultores não possuem. Os produtos de origem animal poderiam ser uma 
alternativa interessante de mercado, o que contribuiria para o desenvolvimento local, aumentando a diversidade de produção das propriedades familiares, visto que há mercado, porém, por falta de um marco legal adequado a produção agroindustrial de pequena escala, investimentos do poder público, falta de poder de cooperação entre os produtores, e de falta de comprometimento de todos os atores que a cercam, ainda há uma deficiência para suprir este nicho de mercado.

Com relação aos sistemas de produção, os agricultores têm encontrado dificuldades para a produção de mudas de hortaliças e na condução de sistemas de produção diferenciados, com os orgânicos, por exemplo. Inclusive, os agricultores têm dificuldade de entender os sistemas orgânicos e qual a diferenciação dos convencionais, acreditam que se reduzirem as quantidades de produtos químicos estariam produzindo de forma orgânica. A falta de produção de mudas de hortaliças pode ser considerada um ponto emblemático no que tange à conservação das espécies e na variabilidade genética encontrada nas propriedades, pois a maioria das famílias de feirantes compra mudas de hortaliças em agropecuárias. Essa questão os deixa a mercê da variedade existente no mercado e não valoriza a adaptação das espécies e a conservação de sementes e de variedades de interesse dos agricultores e dos consumidores. Para Nodari e Guerra (2015), a agrobiodiversidade é imprescindível para a sustentabilidade da agricultura, "pois um dos princípios ecológicos mais importantes nos quais essas práticas se fundamentam é a diversidade de espécies e a diversidade intraespecífica nos agroecossistemas" (p. 186), o que deveria ser acompanhado mais de perto pelas entidades de assistência técnica e extensão rural, além das instituições de pesquisa regionais.

Os agricultores têm enfrentado dificuldades com relação a diversificação e produção sazonal de hortaliças, inclusive de manejo técnico, seleção de variedades mais adaptadas às condições climáticas e manejo de cultivos em ambiente protegidos. Outra área que foi apontada pelos agricultores como deficiente é a gestão da propriedade e dos mercados de circuito curto acessados, pois os mesmos além da feira, comercializam em casa, de porta em porta, sob encomenda e alguns para os mercados institucionais. Essas questões demonstram que a AF necessita de assessoria para a construção de formatos produtivos e tecnológicos adequados à realidade local, coerente com os princípios do desenvolvimento sob os pontos de vista social, ambiental e econômico. Segundo GODOY (2005), torna-se igualmente relevante, abordar as ações que competem ao poder público enquanto mediador desse processo. A segurança alimentar e nutricional é hoje, apontado como assunto obrigatório no campo das políticas públicas e do processo de intervenção estatal.

Os alimentos procedentes de agroindustrialização artesanal ocupam um espaço significativo nas feiras de Júlio de Castilhos e Tupanciretã. Os agricultores afirmaram que os produtos mais procurados e por consequência os mais vendidos na feira são: pães e bolachas, geleias de diversos sabores, mandioca descascada, açúcar mascavo, queijo colonial, banha suína, doces variados. Os produtos agroindustrializados artesanalmente trazem para o imaginário dos consumidores a cultura alimentar de herança colonial onde os alimentos consumidos na feira têm o sabor do alimento produzido pela avó, pela mãe ou outra pessoa da família e hoje não são mais produzidos em casa. Trata-se de um processo de revalorização e de manutenção da cultura alimentar. Canesqui (2005) expõe que embora as pessoas influenciadas pelo modo alimentar do fast-food e da indústria alimentar, as quais introduzem esse tipo de alimentação no cotidiano de suas vidas, elas ainda mantêm um discurso que valoriza a tradicional comida caseira.

Aproximadamente $70 \%$ dos feirantes que comercializam alimentos processados não rotulam seus produtos e afirmam que não gostariam de rotular os mesmos, pois acreditam que isso descaracterizaria os produtos de origem da AF, ou que é economicamente inviável. Essa questão denota as relações de confiança estabelecidas entre os consumidores e agricultores, onde as informações são passadas de um para o outro e não pelas informações contidas nos rótulos, como acontece nos produtos industrializados.

De fato, de acordo com Padilha et. al. (2005), a qualidade dos produtos advindos das agroindústrias, geralmente serão saborosos, diferenciados e de origem conhecida (procedência), além de manter o máximo possível das propriedades nutricionais e degustativas da matéria prima utilizada. Para os autores esses produtos reforçam e preservam a cultura local e regional e, além dos aspectos sociais que estão concomitantemente valorizados, ainda estimulam o associativismo e cooperativismo. A maneira de preparação dos produtos oriundos da agroindustrialização de pequeno porte pode determinar a sua caracterização, ou seja, artesanal, colonial ou, até mesmo, orgânica (WESZ JUNIOR e TRENTIN, 2005). Essas características, para os autores, são fundamentais para a identificação do produto, e estão diretamente relacionadas ao conhecimento no que diz respeito a forma de produção, sendo assim uma forma de diferenciação das pequenas agroindústrias rurais sobre as de maior porte.

Os agricultores familiares no Brasil, após o processo de modernização da agricultura sempre tiveram dificuldades de comercialização de seus produtos sem a presença dos intermediários, ou se tornaram produtores de matéria prima e dependentes de grandes indústrias. Assim a ideia das agroindústrias familiares é um fortalecimento para estes agricultores, pois vai tratar da fabricação de produtos caseiros, em média escala, para venda direta ao consumidor por meio de associações ou feiras dos agricultores (PADILHA et. al. 2005). Para Prezotto (2002), a agroindustrialização não é nenhuma novidade para os agricultores, pois já está intimamente ligada às suas próprias histórias e culturas, objetivando o consumo da família e abastecer o mercado local com o excedente. Como por exemplo, a 
transformação de frutas em doces e bebidas, a elaboração de conservas em geral, fabricação de queijo, embutidos e derivados de carne. Ao entendimento do autor, agroindustrialização é o beneficiamento dos produtos agropecuários e/ou transformação da matéria prima gerando novos produtos.

A comercialização de produtos nas feiras é uma das maneiras de destinar de forma lucrativa os excedentes produzidos nas propriedades, além de caracterizar muitas vezes a produção em escala agroindustrial de pequena escala, como relata Vieira (1998). O autor afirma ainda, que a agroindústria rural é motivada por dois fatores; o aproveitamento de excedentes e agregação de valor aos produtos. A agroindustrialização dos produtos agropecuários é uma alternativa interessante para a sustentabilidade da agricultura familiar, no sentido em que melhora a renda e abre novos postos de trabalhos no meio rural, (PERES et. al., 2009). Peres et al (2009) ainda ressaltam a preservação de ensinamentos passados de pai para filho, muitos agricultores já vêm desenvolvendo estas práticas há bastante tempo, destinando estes produtos para o autoconsumo e ou para suprir demandas locais.

Wesz Junior e Trentin (2005), sustentam que a agroindústria familiar se torna uma alternativa rentável, e até mesmo um meio capaz de trazer a dignidade do campo, empregos diretos e indiretos, valorização das culturas, das identidades, da mulher e do jovem trabalhador, e uma economia descentralizada.

Os agricultores feirantes processam os alimentos em casa em instalações adaptadas ou construídas para a agroindustrialização. Praticamente todas as famílias processam os alimentos somente com a mão de obra familiar. Em torno de $50 \%$ dos produtos são processados com matéria prima exclusiva da propriedade. Enquanto, o restante produz apenas com parte da matéria prima utilizada nos agroindustrializados. Os panificados de modo geral, são produtos que são fabricados com pouca matéria prima oriunda da propriedade, pois o ingrediente principal, a farinha, não é produzida pelos agricultores.

\section{Como os consumidores percebem as feiras?}

As feiras possibilitam o desenvolvimento de uma alimentação mais saudável, além de resgate e preservação da cultura alimentar herdada. Para Mior et al (2013) as vendas diretas permitem uma ampliação das relações sociais entre agricultores e consumidores, além disso ocorre uma expansão da demanda à medida que os produtos se tornam mais conhecidos. Os espaços de comercialização direta, segundo Mior et (2013), são espaços que ressignificam a relação entre produtor e consumidor, pois os mesmos trocam saberes, informações, receitas e impressões. As relações de confiança e de reconhecimento permeiam o processo de troca nas feiras e, de certa forma, respaldam as práticas das famílias agricultoras. "É, portanto, um espaço social de aprendizagem que permite aos agricultores criarem mercados para seus produtos e expandir seus negócios com mais segurança” (MIOR et al, 2013, p.06).

A confiança dos consumidores para com os agricultores e seus sistemas de produção, assim a reputação dos produtos é percebida no estudo realizado na fidelidade dos consumidores, segundo BALEM (2015), a construção de uma relação entre produtores, consumidores e gestores públicos é essencial para que um mercado reconectado, de fato, aconteça. A fidelidade por parte dos consumidores pode ser expressada pela frequência com que tais frequentam a feira, sendo que $60 \%$ dos consumidores admitem frequentar semanalmente. O restabelecimento das relações face a face entre agricultores e consumidores, a demanda por produtos da colônia e a valorização da identidade desses produtos por parte dos consumidores são indicativos de um processo de reenraizamento do sistema agroalimentar local, e a visitação e consumo nas feiras apresentou um público feminino com maior número de consumidores, no entanto, a diferença entre os gêneros não foi de grande expressão, comprovando que são criados estes vínculos independentemente do gênero.

Há evidências de que os jovens vêm se conscientizando quanto a qualidade e a forma de alimentação, pois cerca de $35,4 \%$ dos consumidores possuem idade compreendida entre 18 a 30 anos, em sequência, 22,9\% possuem idade compreendidos entre 61 a 70 anos nas feiras de Júlio de Castilhos. Já no município de Tupanciretã, percebemos uma participação equitativa entre as faixas etárias. Essa participação expressiva de consumidores de várias faixas etárias demonstra que a preocupação com a alimentação e a busca pelo consumo de alimentos com maior identidade e mais saudáveis não está presente somente nos mais velhos e nas gerações menos impactada pelo modelo industrial de alimentação. Para Rozin et al. (2004) umas das questões que tem direcionado as discussões a respeito da alimentação é a preocupação cada vez maior de uma parcela da população com relação à saúde, onde o natural é associado a maiores possibilidades de segurança alimentar e menos problemas de saúde ocasionados pelo artificial. Para os autores o alimento artificial é tratado como sinônimo de alimento processado e ultra processado, proveniente da grande indústria alimentar. O alimento natural, de acordo com Rozin et al. (2004), significa aquele produto que não foi modificado de forma significativa pela manipulação humana, conservando essência quimicamente idêntica ao produto que ainda está no ambiente natural.

No entanto percebemos que $30 \%$ dos consumidores possuem ensino superior completo e $21,42 \%$ ensino superior incompleto, o que demonstra um público com mais acesso à informação e de certa forma maior compreensão do 
benefício do consumo de produtos livres de produtos químicos à saúde e talvez, mais conscientes com relação a diferença entre os alimentos industrializados e ultra processados e sem identificação de procedência.

Percebemos que existe uma alta fidelização dos consumidores, pois $60 \%$ frequentam a feira semanalmente, podendo-se compreender que há uma tradição de "fazer a feira". Quando questionados sobre como foram apresentados à feira, os entrevistados das feiras castilhenses relataram que conheceram por meio de propagandas, seguida pela razão de residência perto do local da feira e indicação de amigos e familiares. Considerando este aspecto, no início das feiras houve ampla divulgação por meio de rádio, redes sociais e até mesmo com promoções dentro das próprias feiras, como café colonial, sorteio de cestas com produtos comercializados no local. No município de Tupanciretã os fatos que levaram os consumidores ao conhecimento da feira foram familiares e amigos, possuir residência perto, muito embora, um dos gargalos mais declarados, segundo os consumidores, é que a feira não possui uma localização tão atrativa ao comércio e também que as instalações não trazem condições de conforto aos consumidores, por ser nas margens de uma avenida movimentada da cidade, por onde escoa grande parcela da produção de grãos do município.

Como critério para consumir os produtos ofertados nas feiras a maior parte dos entrevistados castilhenses relatam que é em razão da qualidade $(81,25 \%)$, e elencam também a origem, tendo assim uma segurança, pois o produto possui origem colonial e logo teria um sabor diferenciado. $86,26 \%$ dos tupanciretanenses entrevistados levam em consideração o requisito da qualidade, seguida pelo fator preço. Nos municípios existem redes de distribuição e comercialização convencional de produtos similares aos ofertados na feira e observamos que nesses casos, não há diferença significativa de preços, embora há consumidores que preferem adquirir os produtos nas feiras por acreditar que os preços são menores. Assim, é possível afirmar que os motivos para comprar dos produtores nas feiras baseiam-se em adquirir alimentos mais saudáveis, com identidade, produtos frescos, além da diversificação ofertada.

E por fim, não menos importante, abordamos sobre produtos orgânicos e agroecológicos. Existe uma preferência por alimentos orgânicos, pois 45 consumidores relatam isso, além de declararem que pagariam mais caro para obter os produtos, com o argumento de que é viável pagar mais pelos benefícios que estes trazem à saúde. Ainda, 61 consumidores disseram conseguir comprar produtos orgânicos nas feiras, no entanto, em nenhumas das feiras há a presença destes produtos, mesmo que os produtos sejam produzidos de forma diferenciada, não há comprovação de produção orgânica. E sete dos consumidores questionados levam em consideração os produtos orgânicos como critério de comprar nas feiras. Os agricultores, quando foram questionados sobre os sistemas de produção, em torno de $40 \%$ afirmaram que não utilizam agrotóxicos nos sistemas de cultivo, mas na sua maioria utilizam adubos químicos. Nenhum agricultor se intitula orgânico ou agroecológico.

Muito embora, os produtos ofertados nas feiras são semelhantes de feirante para feirante, existe uma preferência por parte do consumidor. Por exemplo, há consumidores que só adquirem alimentos de um determinado agricultor feirante, mesmo tendo muitas outras opções na mesma feira. Isso se caracteriza como a fidelidade de consumo, assim estabelecendo uma relação social e cultural, como forma de certificação na aquisição de produtos saudáveis e de boa procedência.

\section{Considerações Finais}

Há muitos aspectos que podem ser explorados nas feiras dos agricultores familiares dos municípios estudados: a importância das feiras como espaços diferenciados de consumo; a identificação das feiras como locais onde é possível comprar um alimento de melhor qualidade; a busca por parte dos consumidores por alimentos com identidade cultural; a dimensão da contribuição social que as feiras possuem, no que tange a geração de renda para os agricultores; e um dos aspectos mais importantes, a consolidação de um espaço diferenciado e com uma identidade de agricultura diferente da identidade hegemônica dos municípios. A presença das feiras em cidades, de certa forma, vem a implantar, manter e disseminar um resgate de cultura alimentar mais saudável, através da diversificação na produção de alimentos, podendo consumir frutas e verduras da época, bem como, obter esses produtos com qualidade e sabor diferenciados, quebrando o paradigma do fast-food, onde o argumento dos consumidores é a falta de tempo para o preparo dos alimentos e a praticidade de poder comer em ambientes onde facilitam a logística para o trabalho.

Podemos analisar também a necessidade de maior assessoria do poder público, quem sabe inserido este assunto nas pautas sobre desenvolvimento rural, no apoio da diversificação dos produtos comercializados, além de investimentos na agroindustrialização, fazendo com que os municípios não precisem consumir produtos dos grandes centros de varejo. Os municípios de Júlio de Castilhos e Tupanciretã possuem uma vasta área para produção de próprio alimento e um número significativo e agricultores familiares que poderiam estar produzindo alimentos não soja. E também ficou evidente que há demanda por produtos de melhor qualidade, porém são necessários incentivos e apoio para os agricultores enfrentar o paradigma da monocultura de soja. É importante considerar que 
os municípios possuem um terreno fértil para a produção em pequena escala e mais sustentável, pois há um grande número de agricultores familiares, grande parte deles provindos de Assentamentos de Reforma Agrária.

Mais estudos sobre a agricultura familiar da nesta região podem servir como "lupa" para públicos desinformados sobre a importância da agricultura familiar, que ainda mantém espaços de produção diversificados, mas por outro lado, também se encontra fortemente impactada pelo monocultivo da soja. Revelando assim, detalhes que escapam ao senso comum, dando possibilidades de ajustes das políticas públicas voltadas a este importante eixo da agricultura, alindo produção diferenciada e mercados de circuito curtos mais consolidados.

\section{Referências}

BALEM, T. A. e SILVEIRA, P. R. C. da. A erosão cultural alimentar e os desafios para a segurança alimentar. In: Guimarães, G. M. et al. O Rural contemporâneo em debate: temas emergentes e novas institucionalidades. Ijuí: ed. Unijuí, 2015. p 187-210.

BALEM, T. A. O programa de alimentação escolar brasileiro e a narrativa alternativa dos alimentos: convergências e desafios. Tese. (Doutorado em Extensão Rural). Universidade Federal de Santa Maria (UFSM-RS), Santa Maria, 2015.

BALEM, T. A; MAROSTEGA, V. R.; SECRETTI, D. Atritos entre homem, natureza e produção agrícola: um olhar sobre os sistemas de produção de leite em Assentamentos de Reforma Agrária em Júlio de Castilhos/RS. In: CONGRESSO DA SOCIEDADE BRASILEIRA DE ECONOMIA, ADMINISTRAÇÃO E SOCIOLOGIA RURAL, SOBER, 49, 2011, Belo Horizonte. Anais... Belo Horizonte: SOBER, 2011. 1 CD-ROM.

Referências

BUCHLER, S., SMITH, K.; LAWRENCE, G. Food risks, old and new. Demographic characteristics and perceptions of food additives, regulation and contamination in Australia. Journal of Sociology, v. 46, n. 4, p. 353$374,2010$.

CANESQUI, A. M. Comentários sobre os Estudos Antropológicos da Alimentação. In: CANESQUI, A. M.; GARCIA, R.W.D. (Orgs.). Antropologia e Nutrição: um diálogo possível. Rio de Janeiro: Editora FIOCRUZ, 2005. p. 23-48.

CERQUEIRA, P. da S.; ROCHA, A. G. P.; COELHO, V. P. Agricultura familiar e políticas públicas: algumas reflexões sobre o Programa de Aquisição de Alimentos no estado da Bahia. In: II ENCONTRO DE ECONOMIA BAIANA - SET./2006. Disponível em: http://www.mesteco.ufba.br/scripts/arquivos/at_ecoreg_05.pdf. Acesso em: 06 de outubro de 2011.

EMATER-RS/ASCAR. Plano de Recuperação do Assentamento (Versão completa): Santa Júlia. Emater-RS/ ASCAR: Júlio de Castilhos, 2009.

FEE. FUNDAÇÃO DE ECONOMIA E ESTATÍSTICA. FEE DADOS: Rio Grande do Sul - agricultura - culturas temporárias - Soja. Porto Alegre. 2015. Disponível em: http://www.fee.rs.gov.br/feedados. Acesso em: 14 abr. 2017.

FRANÇA, F.C.O.; MENDES, A.C.R.; ANDRADE, I.S.; RIBEIRO, G.S.; PINHEIRO, I.B. Mudanças dos Hábitos Alimentares provocados pela industrialização e o impacto sobre a saúde do brasileiro. In. Anais do I Seminário Alimentação e Cultura na Bahia. Disponível em <http://www2.uefs.br:8081/cer/wp-content/uploads/ FRANCA_Fabiana.pdf> Acesso em: 30 de agosto de 2016.

GODOY, W. I. As feiras-livres de Pelotas, RS: estudo sobre a dimensão socioeconômica de um sistema local de comercialização. Tese. (Doutorado em Agronomia), Universidade Federal de Pelotas, Pelotas, 2005.

GOMES, R. Análise e interpretação de dados de pesquisa qualitativa. In: DESLANDES, S. F.; GOMES, R. MINAYO, M. C. de S. (org.). Pesquisa social: teoria, método e criatividade. - 31. Ed- Petrópolis, RJ: Vozes, 2012. p. 79-108.

GoOdMAnN, D. The "Turn Quality" and Alternative Food Practices: Reflections and Agenda. Journal of Rural Studies, v.19, n.1, 2003. 
GUANZIROLI, C. E. PRONAF dez anos depois: resultados e perspectivas para o desenvolvimento rural. RER, v. 45 , n. 02, p. 301-328, abr/jun 2007.

GUANZIROLI, C.; CARDIM, S. E. (Coord.). Novo Retrato da Agricultura Familiar: O Brasil redescoberto.

Brasília: Projeto de Cooperação Técnica FAO/INCRA, fev/2000. 74 p. Disponível em: http://www.incra.gov.br/faol pub3.html. Acesso em: 02 de março 2012.

GUANZIROLI, Carlos Enrique; BUAINAIN, Antônio Marcio; DI SABBATO, Alberto. Dez anos de evolução da agricultura familiar no Brasil: (1996 e 2006). Rev. Econ. Sociol. Rural [online]. 2012, vol.50, n.2, pp.351-370. ISSN 0103-2003. http://dx.doi.org/10.1590/S0103-20032012000200009.

IBGE (INSTITUTO BRASILEIRO DE GEOGRAFIA E ESTATÍSTICA). IBGE Cidades. Disponível em: https:// cidades.ibge.gov.br/brasil/rs/. Acesso em: 31 de Agosto de 2018.

IBGE, Produção Agrícola Municipal 2017. Rio de Janeiro: IBGE, 2017.

KUHN, T. S. A estrutura das revoluções científicas. São Paulo: Perspectiva, 2011.

INSTITUTO BRASILEIRO DE GEOGRAFIA E ESTATÍSTICA. Censo Agropecuário 2006 e Censo Demográfico 2010 - Cidades. Disponível em: http://migre.me/uCCtx . Acesso em: 15 de março de 2017.

LAVILLE, C.; DIONNE, J. A construção do saber: manual de metodologia da pesquisa em ciências humanas. Porto Alegre: Editora Artes Médicas Sul Ltda.; Belo Horizonte: Editora UFMG, 1999.

MINISTÉRIO DO DESENVOLVIMENTO AGRÁRIO. BRASIL. Agricultura familiar no Brasil e o censo 2006. Brasília: MDA, 2009.

MIOR, Luiz Carlos et al. Caracterização das agroindústrias familiares e das redes de cooperação no sul catarinense. Disponível em: http://intranetdoc.epagri.sc.gov.br/producao tecnico cientifica/DOC 34517.pdf. Acesso em: 20 março 2017.

MORIN, Edgar. O método 3: o conhecimento do conhecimento. Porto Alegre: Sulina, 1999.

MOREIRA, V. S. Territorialidades rurais em Júlio de Castilhos - RS: da pecuária extensiva à agricultura familiar. Dissertação (Programa de Pós-Graduação em Geografia e Geociências), Universidade Federal de Santa Maria. Santa Maria, 2008.

MOREIRA, Vinicius Silva; MEDEIROS, Rosa Maria Vieira. A reestruturação territorial através de assentamentos rurais: o caso do município de Tupanciretã / RS. In Encontro grupos de pesquisa: Agricultura, desenvolvimento regional e transformações sócio espaciais, 5. Santa Maria, 2009. Disponível em: http://w3.ufsm.br/gpet/engrup/ vengrup/anais/1/Vinicius\%20Moreira_UFRGS.pdf. Acesso em: 20 de março 2017.

NODARI, Rubens Onofre; GUERRA, Miguel Pedro. A agroecologia: estratégias de pesquisa e valores. Estudos avançados, v. 29, n. 83, p. 183-207, 2015.

PADILHA, P. R. P.; FERREIRA, A. R. M. R.; TRETIN, I. C. L. Viabilidade da agroindústria familiar orgânica. In: CONGRESSO DA SOCIEDADE BRASILEIRA DE ECONOMIA, ADMINISTRAÇÃO E SOCIOLOGIA RURAL, SOBER, 43, 2005, Ribeirão Preto. Anais... Brasília: SOBER, 2005.

PERES, A.P.; RAMOS, V.G.; WIZNIEWSKY, C.R.F. A produção de derivados de cana-de-açucar como alternativa para a agricultura familiar; um estudo de caso na Agroindústria familiar rural. In.: Encontro Nacional de Geografia Agrária, 19. São Paulo, 2009, pp. 1-19. Disponível em: http://migre.me/wjGEQ Acesso em: 31 de agosto de 2016.

PICOLOTTO, E. L. Os Atores da Construção da Categoria Agricultura Familiar no Brasil. RESR, Piracicaba-SP, Vol. 52, Supl. 1, 2015, p. S063-S084. 
POUlAIN, J. P. Sociologias da Alimentação: os comedores e o espaço social alimentar. Florianópolis: Editora da UFSC, 2004.

PREZOTTO, L. L. Qualidade ampla: referência para a pequena agroindústria rural inserida numa proposta de desenvolvimento regional descentralizado”. In: LIMA, D. M. de A. e WILKINSON, J. (Orgs.) Inovações nas tradições da agricultura familiar. Brasília: CNPq/Paralelo 15, 2002. p. 285-300.

ROZIN, P. et al. Preference for natural: instrumental and ideational/moral motivations, and the contrast between foods and medicines. Appetite, n. 43, 2004, p. 147-154.

SCARABELOT, M.; SCHNEIDER, S. As Cadeias Agroalimentares curtas e desenvolvimento Local - um estudo de caso no Município de Nova Veneza - SC. Revista Faz Ciência, Volume 15 - Número 20- Jan/Jun 2012 - pp. 101-130. Disponível em: http://migre.me/wjGCX. Acesso em: 23 de setembro de 2016.

VIEIRA, L. F. Agricultura e Agroindústria Familiar. Revista de Política Agrícola - Ano VII - No 01 - Jan-FevMar 1998.

WESZ JUNIOR, V. J.; TRENTIN, I. C. L. Desenvolvimento territorial com agroindústrias familiares. 2005. Disponível em http://www.sober.org.br/palestra/2/468.pdf . Acessado em 31 de agosto de 2016.

WISKERKE, J.S.C. On places lost and places regained: reflections on the alternative food geography and sustainable regional development. International Planning Studies, v. 14, n. 4, p. 369 -387, 2009. 